\title{
APPETITE CONTROL AND ENERGY (FUEL) BALANCE
}

\author{
JOHN E. BLUNDELL ${ }^{1}$ AND ANGELO TREMBLAY ${ }^{2}$ \\ 'BioPsychology Group, Psychology Department, University of Leeds, Leeds LS2 9JT, \\ UK \\ ${ }^{2}$ Laboratoire des sciences de l'activité physique (PEPS), Université Laval, Ste Foy, \\ Quebec, Canada, G1K 7P4
}

\section{CONTENTS}

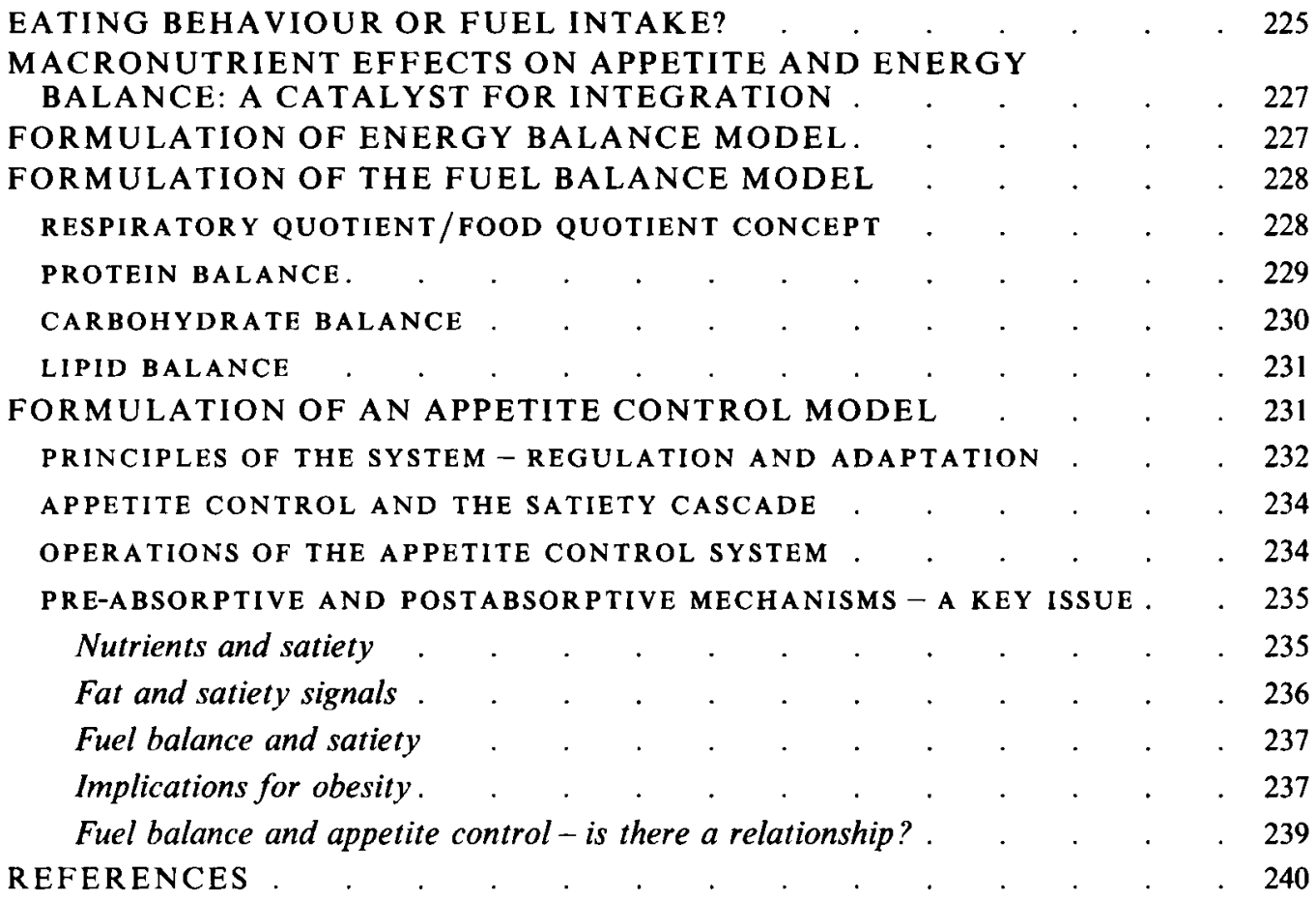

\section{EATING BEHAVIOUR OR FUEL INTAKE?}

For well over 50 years, attempts to explain the mechanisms responsible for human food consumption and the regulation of body weight have been the subject of serious research. Within the last two decades or so this scientific undertaking has gained in importance through the need to understand human obesity and to develop strategies to treat or prevent it. Physiologists, nutritionists, psychologists, biochemists, endocrinologists, pharmacologists and others have made significant contributions, and in the plethora of published articles some clear themes are detectable. Both the school of appetite control and the school of energy balance have generated an impressive array of research findings. These two 
approaches have tended to evolve separately from each other and to run in parallel. Is an integration of these two approaches possible? Would it be helpful?

The appetite and the energy balance researchers share, as one of their primary goals, the attempt to understand human food consumption but the basic terminology which refers to this end point is often different. In the appetite field the phenomenon usually measured is called eating, human feeding or food intake. Among energy balance researchers the phenomenon is usually called dietary intake, energy intake or more commonly spontaneous energy intake. Differences between the approaches are also apparent at a more fundamental level. Appetite research is often concerned with qualitative aspects of eating such as food choice, preferences and the sensory aspects of food, together with subjective phenomena such as hunger, fullness and hedonic sensations which accompany eating and are sometimes regarded as causal agents. The energy balance approach is primarily concerned with quantitative aspects of eating and with the energy value of food. Also seen as important is the macronutrient composition of food and its impact on energy balance. While appetite research views eating as a form of behaviour, energy balance research regards eating as fuel intake.

It is not surprising that these separate concepts have arisen from separate scientific disciplines with different ideologies. Research on appetite control has been heavily influenced by psychologists; energy balance research has been the province of physiologists, biochemists and nutritionists. Appetite research usually incorporates motivation as central to the control of eating. In turn this motivation may arise from social or environmental stimuli as well as from within the organism. The physiological approach is based on a more deterministic view of eating in which energy intake is viewed as the end result of internal physiological or metabolic processes.

The two approaches also differ in procedures and methods. Appetite research has often used short-term studies, concentrating on local effects on eating, i.e. stimuli or manipulations operating within hours or sometimes minutes. Often the effects of such manipulations on eating over a whole day or longer are not measured and remain unknown. Energy balance research usually involves experiments lasting for $24 \mathrm{~h}$ or longer with concurrent measurements of energy intake, expenditure and intermediary metabolism.

The distinctions between the two approaches can be extended. Firstly it is clearly valid to investigate the many and varied ways in which food affects human functioning, both psychological and physiological. Secondly, the two approaches are not completely separate. There has always been a certain overlap of approaches and the application of interdisciplinary science. This has been apparent in the so-called metabolic approach to appetite - a field of study shared by physiologically minded psychologists, biochemists, physiologists and others (e.g. Friedman, 1990). However, the search for metabolic processes which influence human eating, while necessarily included in an energy balance approach, can also exist separately. Indeed, the effects of metabolic stimuli on food intake have often been studied short term, which is more in common with the appetite school than the energy balance approach (e.g. Langhans \& Scharrer, 1987).

Simultaneous consideration of behaviour and physiology should produce a stronger scientific base. A response to a behavioural or nutritional manipulation does not have to be behavioural; physiological or metabolic adaptation could also occur. However, if physiological variables were not being measured then it could be inferred that the manipulation was ineffective.

The two approaches come into conflict when they attempt to explain 'abnormal' eating and its consequences for weight gain. Is obesity brought about by enhanced feelings of hunger, weakened satiety, sensorily induced overconsumption or hedonically mediated maladaptive food choices? Or is obesity a result of inadequate oxidation of fuels, errors in 
the processes governing energy balance, or different metabolic responses to dietary intake? Are these apparently distinctive modes of explanation mutually incompatible? The objective of this chapter is to seek common ground and to prepare a better integration between these approaches.

\section{MACRONUTRIENT EFFECTS ON APPETITE AND ENERGY BALANCE: A CATALYST FOR INTEGRATION}

In recent years separate approaches to the study of human eating have been drawn together by the recognition of the role of macronutrients in the development of obesity. Many studies have found a significant correlation between body mass index and the percentage of fat consumed in the diet. Other studies have drawn attention to the role of low fat (low energy dense) and high carbohydrate foods as an appropriate dietary approach to the treatment of obesity (e.g. Kendall et al. 1991; Shah et al. 1994). There has been an interest in the relative satiating power of protein, fat and carbohydrate and most studies agree that protein produces the most potent control of food intake (e.g. De Castro, 1987; Hill \& Blundell, 1988). It is of course necessary to ensure that protein intake is carefully controlled and is independent of changes in energy intake. Some studies have suggested that perturbed protein metabolism can have a pronounced effect on intake. However, recent studies in the field of obesity have concentrated attention on the respective capacities of carbohydrate and fat to promote overconsumption, and particularly the possibly weak capacity of fat to limit food intake.

During this same period the work of J.P. Flatt has influenced thinking about the relationship between macronutrient intake (i.e. the diet consumed) and energy balance. The essence of this approach is that carbohydrate balance (relationship between intake and expenditure) is tightly controlled, like protein, but fat balance is poorly controlled. This means that fat intake is poorly coupled to its utilization and in the case of positive balance the excess will be stored. It therefore seems advantageous to use information about macronutrients as a tool to explore avenues of integration between appetite control and energy balance.

\section{FORMULATION OF ENERGY BALANCE MODEL}

Energy balance is observed when energy intake equals energy expenditure. Any change, therefore, in body energy stores, be it associated with psychological or biological factors, necessarily results from an imbalance between energy intake and expenditure. Energy balance may well be achieved by physiological regulation. This suggests that appetite is under the control of a system which monitors energy, and that variations in intake of each macronutrient have no effect on total energy intake since a system counting calories would inhibit appetite when a given energy intake was reached.

Experimental data show that appetite is not mainly controlled by such a system. Thus, recent human studies have been conducted to determine the impact of diet composition on daily energy intake under ad lib. intake conditions. As summarized in Table 1, spontaneous daily energy intake is substantially increased on a high fat compared to a low fat diet. Thomas et al. (1992) reinvestigated this issue in a context where subjects could request additional food portions to reach satiety. Even under these conditions which imposed some psychological constraint on subjects, a high fat diet was found to be accompanied by a significant increase in energy intake. However, in comparisons between high and low fat 
Table 1. Mean ad lib. daily energy intake (MJ) under low fat and high fat diet conditions

\begin{tabular}{|c|c|c|c|}
\hline Reference & Low fat & High fat & Difference \\
\hline Lissner et al. 1987 & $8 \cdot 7$ & $11 \cdot 4$ & $2 \cdot 7$ \\
\hline Tremblay et al. 1989 & $12 \cdot 5$ & $17 \cdot 3$ & 4.8 \\
\hline Tremblay et al. $1991 a, b$ & & & \\
\hline Study $1(1991 a)$ & 13.6 & $15 \cdot 7$ & $2 \cdot 1$ \\
\hline Study $2(1991 b)$ & $13 \cdot 2$ & $15 \cdot 1$ & 1.9 \\
\hline
\end{tabular}

diets at the same energy density, marked overconsumption of the high fat diet is not seen (Van Stratum et al. 1978). However, underconsumption with the low fat (high carbohydrate) diet is observed (Stubbs, 1993).

These observations show that a change in food habits favouring lipid intake has an immediate impact on energy intake and energy balance. They also suggest that energy intake cannot be the 'tensive' variable that is monitored by the system to ensure homeostasis but rather energy intake seems to reflect fluctuations in other variables exerting a more critical regulatory role on some physiological functions. In fact, as further discussed, appetite control may be affected by mechanisms responsible for fuel balance which indirectly influence energy intake and energy balance.

\section{FORMULATION OF THE FUEL BALANCE MODEL}

The notion that appetite is driven by the need for macronutrients was introduced several decades ago and still remains the basic rationale underlying some classical theories of food intake control. These ideas take the form of the glucostatic (Mayer, 1953), aminostatic (Mellinkoff et al. 1955) and lipostatic (Kennedy, 1953) hypotheses of appetite control. Accordingly, the respective roles of protein, carbohydrate and lipid metabolism on food intake have been the subjects of many investigations but these various endeavours have rarely provided an integrated view of the role of macronutrient metabolism on feeding behaviour. In the next section, an integration of recent research observations will be attempted to analyse the potential association between macronutrient (fuel) and energy balance.

\section{RESPIRATORY QUOTIENT/FOOD QUOTIENT CONCEPT}

Indirect calorimetry chambers have greatly facilitated the study of fuel oxidation in a context which closely mimics a habitual physical activity profile. One of the major findings is a very close relationship between fuel balance and energy balance. Specifically, it has been shown in animals (Flatt, 1987) and humans (Jéquier, 1990) that energy balance is strongly correlated with the respiratory quotient $(\mathrm{RQ}) /$ food quotient $(\mathrm{FQ})$ ratio. In physiology, the measurement of substrate oxidation under steady state conditions is based on RQ which then represents a marker of the composition of the fuel mix oxidized. Food quotient or FQ corresponds to the theoretical RQ of foods. It represents an indicator of the composition of the fuel mix ingested, i.e. an overall marker of diet composition. Thus, the RQ/FQ ratio reflects fuel balance when measured under stable standardized conditions.

The demonstration of a strong link between energy and fuel balance suggests that when metabolic studies are performed without the confounding effects of psychological problems 

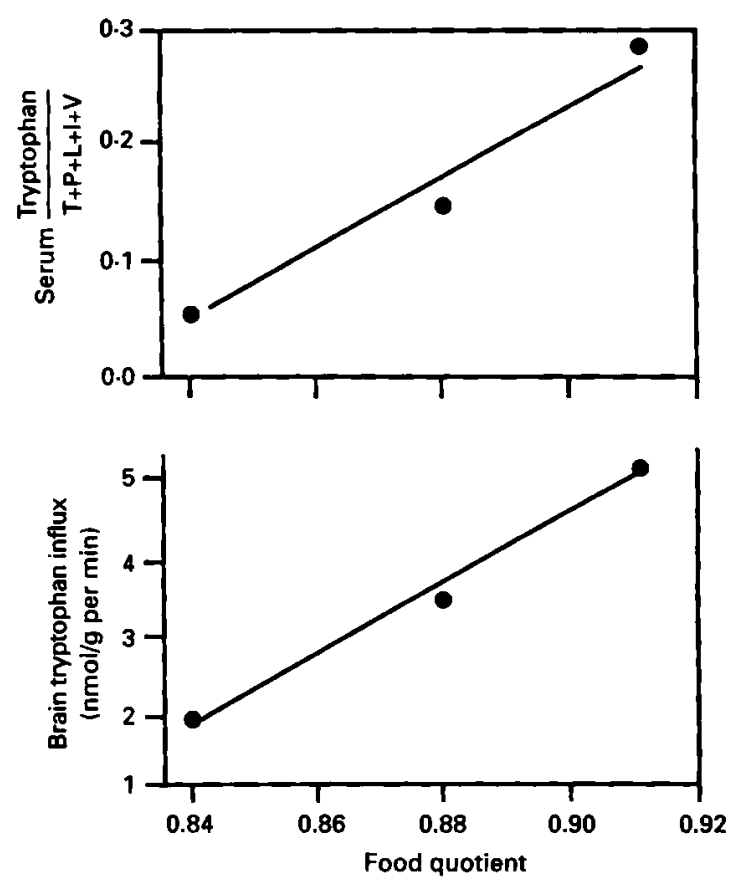

Fig. 1. Association between the ratio of serum tryptophan/large neutral amino acids or brain tryptophan influx and food quotient. Adapted from Fernstrom \& Faller (1978).

and eating disorders, fuel balance summates to determine energy balance. The corollary of this observation is that specificities of each component of fuel balance, i.e. protein, carbohydrate and lipid balance, must be considered as potential effectors which can ultimately influence energy balance.

\section{PROTEIN BALANCE}

Protein accounts for about $15 \%$ of body weight and plays a major structural role in the composition of the body. The quantitative importance of this macronutrient as a fuel is generally small, corresponding to $10-15 \%$ of energy intake and expenditure.

In the fuel balance model, the main characteristic of the protein component is its ability to be regulated over a wide range of intakes. Indeed, it is well established that within this range, protein utilization varies proportionally with protein intake (Young \& Marchini, 1990). Thus, protein utilization is regulated by its intake and the body has the flexibility to prevent protein imbalance under normal feeding conditions. Therefore, it is unlikely that substantial body energy deficit and excess may be mainly attributable to protein imbalance.

Beyond the possibility that protein balance per se might be responsible for variations in energy balance, some experimental evidence suggests that changes in the proportion of circulating amino acids may be involved in a sequence of events affecting appetite. Specifically, it has been proposed that an increase in the serum concentration of tryptophan relative to the other large neutral amino acids favours a preferential uptake of this amino acid by the brain, which would ultimately lead to an increase in serotonin production and an alteration in food consumption (Fernstrom \& Wurtman, 1972). It is not the purpose of 


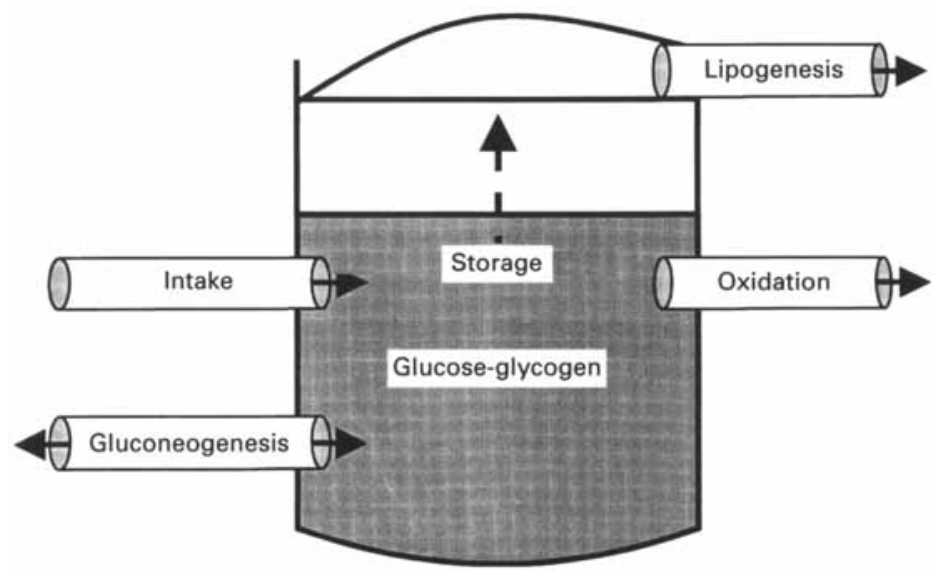

Fig. 2. Schematic view of the main components of carbohydrate balance.

this review to analyse this hypothesis or to assess its validity. However, it is interesting to note the association between the tryptophan/large neutral amino acids ratio and diet composition. As shown in Fig. 1, there is a good relationship between this ratio or brain levels of tryptophan and FQ. Up to now, the association between circulating amino acids and $F Q$ as well as its implications for the regulation of fuel balance have not been investigated but probably deserve some attention.

\section{CARBOHYDRATE BALANCE}

Carbohydrate is generally the main fuel for energy metabolism and contributes the major part of energy intake. This is particularly important for the brain whose metabolism is dependent on glucose under normal feeding conditions, although with a daily requirement of only $100 \mathrm{~g}$ glucose $(1.7 \mathrm{MJ})$, it is unlikely that this need constitutes a strong drive to eat. Despite the role of carbohydrate in energy metabolism, the body stores of this nutrient are very low, corresponding to about the level of daily carbohydrate intake. It seems, then, that the body has a very limited capacity to store its most important fuel. This apparent weakness is however compensated by robust regulatory mechanisms that maintain a minimal carbohydrate supply under restrictive conditions or prevent excessive storage when carbohydrate intake is high for a long period. As depicted in Fig. 2, carbohydrate intake is complemented by gluconeogenesis whose glucose production becomes crucial under conditions of marked carbohydrate restriction. The resulting short term decrease in carbohydrate oxidation also contributes significantly to maintaining carbohydrate balance (Stubbs et al. 1993). On the other hand, when excessive carbohydrate intake is sustained over many days, the acute increase in carbohydrate oxidation and storage may be inadequate to accommodate the total carbohydrate excess. De novo lipogenesis can then be substantially increased (Acheson et al. 1988) to keep body stores of carbohydrates within normal narrow limits.

When these mechanisms are compared to those regulating protein and lipid balance, carbohydrate balance appears to be the most rapidly and precisely regulated. In the context of this review, the main question to be addressed is which are the main features of carbohydrate metabolism sensed by the system.

In his original version of the glucostatic theory, Mayer proposed that plasma glucose variations affect appetite control but he finally proposed that food intake is controlled by 
the cellular availability and utilization of glucose (Mayer \& Thomas, 1967). Initially, Russek suggested that hepatic glycogen stores (or some factor related to hepatic glucose metabolism) exerted negative feedback on food intake. Flatt (1987), in turn, proposed that the level of glycogen stores could be the main glucostatic factor, whereas Campfield $e t$ al. (1985) emphasized the role of preprandial hypoglycaemia as a signal for hunger. Although these observations do not clearly identify the main hunger signal emerging from the carbohydrate component, they nevertheless emphasize the priority that is given to its regulation. In the fuel balance model, the importance of a precise regulation of carbohydrate balance is considered a major determinant of fuel and energy balance.

However, there is an interesting paradox involving carbohydrate metabolism. On one hand, carbohydrate shows autoregulatory changes in its own oxidation but on the other hand it suppresses fat oxidation. Therefore carbohydrate could be considered as fattening (spares fat oxidation) or not fattening (autoregulatory oxidation). The potency of these effects under different environmental and physiological conditions remains to be worked out.

\section{LIPID BALANCE}

Lipid generally accounts for the major part of the body energy content and its contribution to daily energy intake varies between 25 and $50 \%$. Daily lipid utilization also varies within this range and must equal the overall lipid input (including de novo lipogenesis) to maintain fat stores at a constant level. The physiological characteristics of lipid metabolism and balance tend to suggest that the main function of adipose tissue is the storage of triglycerides.

In comparison to the protein and carbohydrate components of fuel balance, lipid balance has certain peculiarities which affect fuel and energy balance. Firstly, there is no metabolic pathway which can serve as overflow when lipid intake largely exceeds fat oxidation. Indeed, this contrasts with protein balance which can transfer the carbon fraction of amino acids to the carbohydrate component. Moreover, as shown in Fig. 2, carbohydrate can be converted into lipid when the increase in storage and oxidation are not sufficient to buffer an excess in carbohydrate intake. Thus, lipid seems to be the only component of fuel balance which can rely only on changes in oxidation to balance its intake.

The second aspect of lipid balance is the inability of lipid oxidation to adapt acutely to a change in lipid intake. This was demonstrated by Flatt $e t$ al. (1985) who found that supplementing a breakfast with a substantial quantity of margarine had essentially no effect on fat oxidation for $9 \mathrm{~h}$. Lipid balance thus appears to be the weak component of fuel balance since a change in intake is not accompanied by a short term metabolic response which could rapidly restore lipid balance.

The factors determining fat oxidation are not clearly established but experimental evidence suggests that gain in body fat is associated with increased fatty acid mobilization, which provides a lipid gradient favouring fat oxidation (Groop et al. 1991). Increased sympathetic nervous system activity, mediated by $\beta$-adrenergic stimulation, also enhances lipid oxidation even when fat stores are low, as recently reported in exercise trained individuals (Tremblay et al. 1992).

\section{FORMULATION OF AN APPETITE CONTROL MODEL}

The expression of human appetite can be perceived as including a drive for energy, conscious sensations of hunger, preferences for particular tastes, selection of specific nutrients, cravings for certain foods and a defined pattern of eating behaviour. In recent 


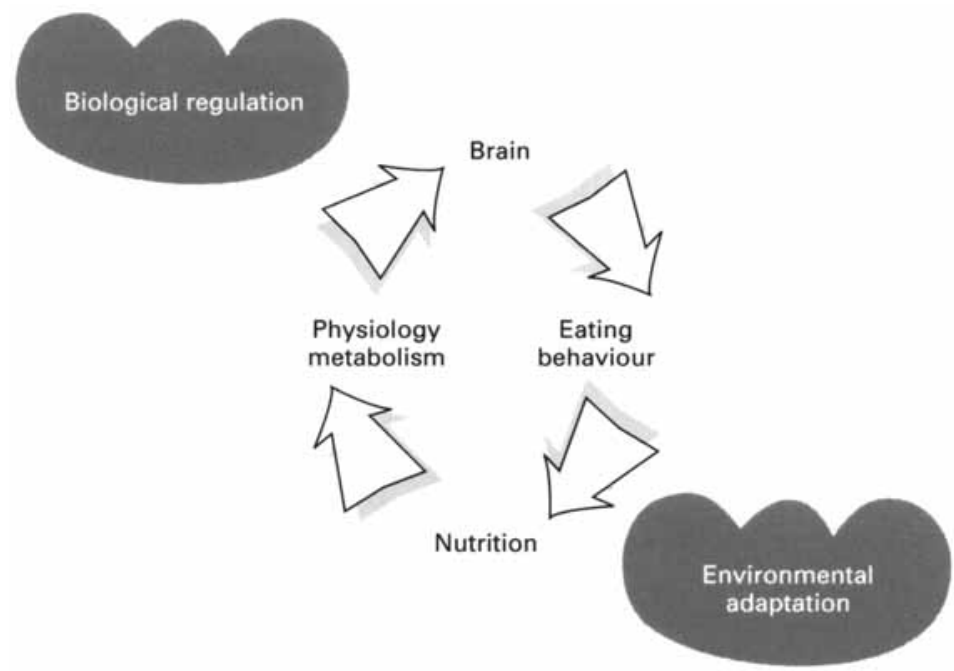

Fig. 3. Schematic diagram to illustrate that the pattern of eating behaviour arises from an interaction between biological regulation and environmental adaptation. Eating is a product of both biology and culture.

years this expression has come to be regarded as the output of a 'psychobiological system' (Blundell \& Hill, 1986; Blundell, 1991 a).

\section{PRINCIPLES OF THE SYSTEM - REGULATION AND ADAPTATION}

A consideration of anthropological, epidemiological and experimental evidence suggests that it is easier for human beings to gain than to reduce weight. This implies that the control of appetite (by the psychobiological system) is asymmetrical. Fig. 3 shows how this arises. The extension of Claude Bernard's principle of homeostasis to include behaviour has been referred to as the behavioural regulation of internal states (Richter, 1943). Logic demands that behaviour (eating) is controlled in accordance with biological states of need. This constitutes a form of biological regulation. However, the expression of behaviour is also subject to environmental demands, and behaviour is adapted in the face of particular circumstances. In the case of human appetite, consideration should be given to the conscious and deliberate control over eating behaviour. Human beings can decide to alter their own behaviour to meet particular objectives, for example, a display of moral conviction (political hunger strike) or a demonstration of aesthetic achievement (e.g. dieting). In both of these examples eating is curtailed thereby interrupting the nutrient supply.

Regulatory mechanisms will tend to oppose this undersupply and generate a drive to eat. In many parts of the world environmental adaptation also means adjusting to a food supply characterized by an abundance of palatable, energy-dense (mainly high fat) foods or by a large proportion of fatty items. Exposure to such diets usually gives rise to an overconsumption of energy. Since this does not appear to be biologically driven (by a need state) or consciously intended, this phenomenon has been referred to as passive overconsumption (Blundell et al. 1993). This, in turn, interacts with genetic vulnerability leading to an increase in fat deposition (Bouchard, 1985). A good example of this is the changes in dietary habits and levels of obesity occurring in the Pacific Islands of Polynesia and Micronesia (Zimmet, 1992). This appears to be due to the high energy density of foods 


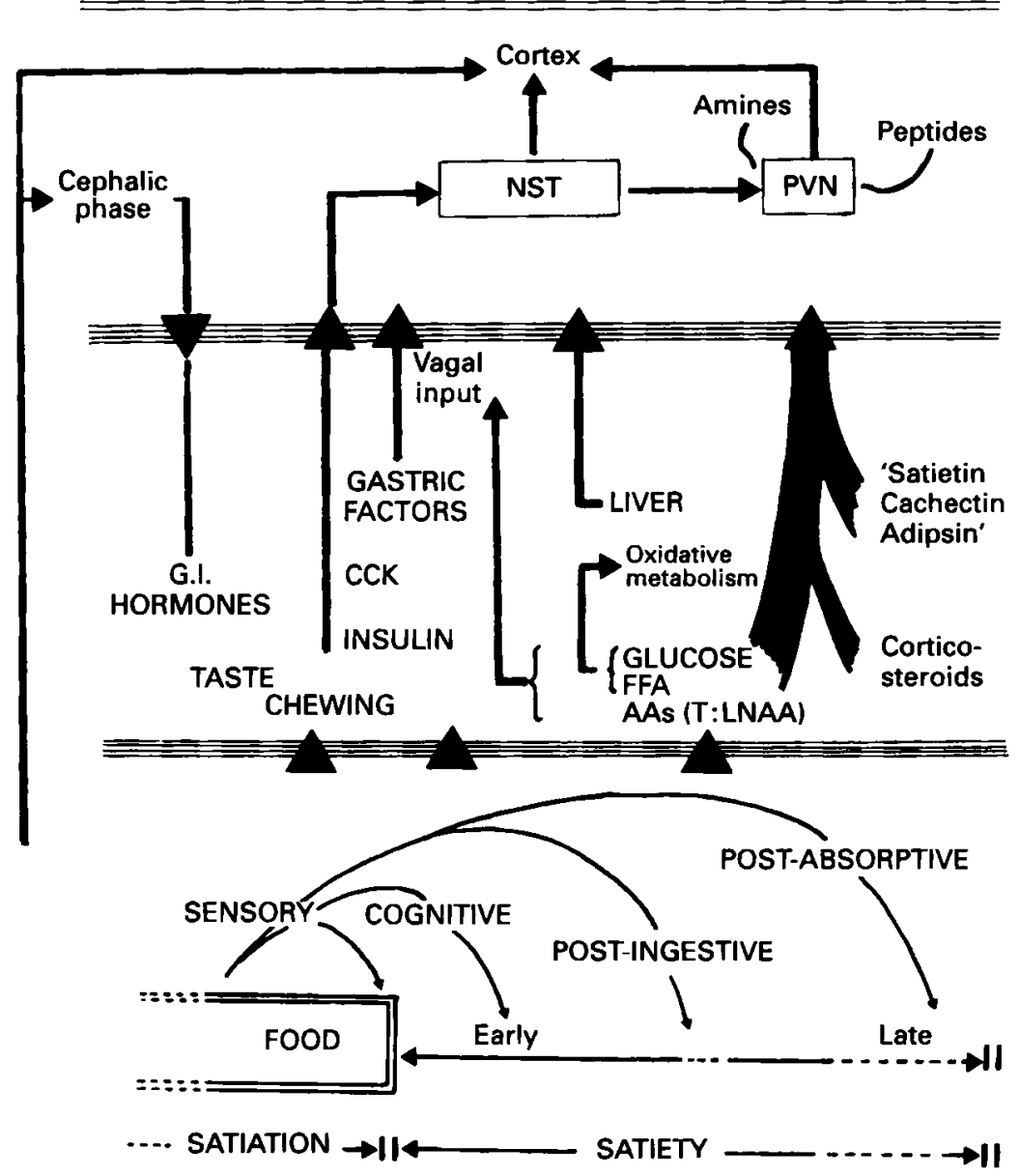

Fig. 4. Diagram showing the expression of appetite as the relationship between three levels of operations: behaviour, peripheral physiology and metabolism, and brain activity. PVN, paraventricular nucleus; NST, nucleus of the tractus solitarius; CCK, cholecystokinin; AA, amino acids; FFA, free fatty acids; T: LNAA, tryptophan: large neutral amino acids.

and since fat is the most dense nutrient, fat contributes most to the energy density and therefore most to the phenomenon of passive overconsumption. But it should be remembered that a number of nutrient and sensory features of foods may contribute in differing degrees to the stimulation of hyperphagia.

However, this passive overconsumption leading to the accumulation of body fat does not appear to generate any biological drive to undereat. Indeed, it is now well accepted that energy intake of obese individuals is, on average, greater than that of lean subjects in order to attain balance with the higher rate of energy expenditure (Prentice et al. 1989). Obese people do not get any help from their adipose tissue to reduce their appetites (although eventually the increase in fat deposits will increase fat oxidation and ultimately restore fat and energy balance). Hence, the operation of the regulatory system is not symmetrical. Two principles may be deduced. Firstly, that biological processes exert a strong defence against undereating which serves to protect the body from an energy (nutritional) deficit. Therefore undereating must normally be an active and deliberate process. Secondly, in general 
biological defences against overconsumption are weak or inadequate. This means that overeating may occur despite the best efforts of people to prevent it. In contrast to undereating (dieting), overeating can be a passive process.

\section{APPETITE CONTROL AND THE SATIETY CASCADE}

How do the mechanisms of appetite control reflect the principles which appear to guide the function of the system? One way to think about this issue is to consider how eating behaviour is held in place by the interaction between the characteristics of food and the biological responses to ingestion. These biological responses are often thought of as satiety signals.

The biological drive to eat can be linked with the satiating power or efficiency of food - the capacity of any consumed food to suppress hunger and to inhibit the onset of a further period of eating. Food brings about this effect by certain mediating processes that can be roughly classified as sensory, cognitive, postingestive and postabsorptive. The operation of these processes results from the effects of food on physiological and biochemical mechanisms. Collectively these processes (Fig. 4, lower panel) have been referred to as the satiety cascade. The way that food is sensed and processed by the biological system generates signals, neural and humoral, which control appetite. It follows that any selfimposed or externally applied reduction in the food supply, creating a calorie deficit, will weaken the satiating power of food. One consequence of this will be the failure of food adequately to suppress hunger (the biological drive). The satiety cascade appears to operate as efficiently in obese people as in lean individuals. Therefore, a normal appetite response to reduced calorie intake is evident in obese subjects.

Technically, satiety can be defined as the inhibition of hunger and eating that arises as a consequence of food consumption. It can be distinguished from satiation, which is the process that brings a period of eating to a halt. Consequently, satiation and satiety act conjointly to determine the pattern of eating behaviour and the accompanying profile of motivation. Together, these two processes therefore control events going on within meals or between meals. The conscious sensation of hunger is one index of motivation and reflects the strength of satiation and satiety. Hunger as a biologically useful sensation is a nagging, irritating feeling that prompts thoughts of food and reminds us that the body needs energy; it can therefore be used as one index of the drive for food and as a consequence of the appetite control system.

\section{OPERATIONS OF THE APPETITE CONTROL SYSTEM}

The biopsychological system concerned with the expression of appetite can be conceptualized on three levels (see Fig. 4): the level of psychological events (hunger perception, cravings, hedonic sensations) and behavioural operations (meals, snacks, energy, and macronutrient intakes); the level of peripheral physiology and metabolic events; and the level of neurotransmitter and metabolic interactions in the brain. The expression of appetite reflects the synchronous operation of events and processes at the three levels. Neural events trigger and guide behaviour, but each act of behaviour involves a response in the peripheral physiological system; in turn, these physiological events are translated into brain neurochemical activity. This brain activity represents the strength of motivation and the willingness to refrain from feeding.

The system can obviously be described in much greater detail (see Blundell, 1991b); however, the important issue is that the expression of appetite does not exclusively represent processes concerned with the utilization of energy in the body but also reflects other types of physiological events. Indeed, the brain is sensitive to information generated 
by various aspects of peripheral physiology. How can this systems approach to appetite control be related to the idea of food intake seen as a response to energy (fuel) utilization?

\section{PRE-ABSORPTIVE AND POSTABSORPTIVE MECHANISMS - A KEY ISSUE}

Even before food touches the mouth, physiological signals are generated by the sight and smell of it. These events constitute the cephalic phase of appetite (Powley, 1977). Cephalic phase responses are generated in many parts of the gastrointestinal tract; their function is to prepare for the ingestion of food.

During and immediately after eating, afferent information provides the major control over appetite. It has been noted that "afferent information from ingested food acting in the mouth provides primarily positive feedback for eating; that from the stomach and small intestine primarily negative feedback" (Smith et al. 1990, p. 63). This draws attention to the relative potency of oral and postingestive stimulation in controlling the amount of food which is eaten.

Initially the brain is informed about the amount of food ingested and its nutrient content via afferent input. This afferent information constitutes one class of 'satiety signals' and forms part of the postingestive control of appetite. It is usual to identify a postabsorptive phase that arises when nutrients have undergone digestion and have crossed the intestinal wall and entered the circulation. These products, which accurately reflect the food consumed, may be metabolized in peripheral tissues or organs or may enter the brain directly via the circulation. In either case, these products constitute a further class of satiety signals. There is evidence that the degree of oxidative metabolism of glucose and free fatty acids in the liver constitutes a significant source of metabolic information which influences the expression of appetite (Friedman et al. 1986).

It is clear that the distinction between pre-absorptive and postabsorptive mechanisms of appetite control is one of the key differences between the appetite and energy balance approaches to the control of food intake. Within the energy (or fuel) balance models the products of ingestion must undergo absorption before they are able to participate in metabolic processes. Consequently, the fuel balance approach makes use exclusively of postabsorptive events. To what extent is the control of food intake dependent upon postabsorptive processes? Do these postabsorptive processes control the periodic initiation and termination of eating? Do they influence the preference for, and the selection of, particular nutrients?

How important are pre-absorptive events - mainly taking place in or around the gastrointestinal tract - for the control of eating behaviour and the pattern of food intake? There is good evidence for potent pre-absorptive satiety signals. If these signals influence food consumption how can this be reconciled with the idea of an exclusive control of energy intake by postabsorptive (energy sensing) mechanisms? This issue can be explored by considering the way in which nutrient intake may affect fuel balance and satiety in relation to the development of obesity.

\section{Nutrients and satiety}

The satiety cascade implies that foods of varying nutritional composition will engage differently with the mediating processes and will therefore exert differing effects upon satiation and satiety. A procedure widely used to assess the action of food on satiety is the preload strategy. Provided that no contaminating stimuli are introduced between the preload and the test meal (Blundell \& Rogers, 1991, 1994) this procedure can be used to assess the satiating power of a wide variety of foods varying in macronutrient composition. 
It is generally accepted that dietary protein exerts a potent effect on satiety (De Castro, 1987 ) and provides the strongest inhibition over appetite. This is in keeping with the maintenance of protein intake at $11-14 \%$ of daily energy, suggesting that the intake of protein is tightly controlled.

Following overconsumption of carbohydrates, the digested carbohydrate influences a number of mechanisms involved in satiety. These include glucoreceptors within the gastrointestinal tract (Mei, 1985) that send afferent information via the vagus and splanchnic nerves and cells in the liver that respond to glucose to the nucleus tractus solitarius and hypothalamic regions of the brain which monitor postabsorptive effects of glucose (Oomura, 1988). These mechanisms form the basis of the so-called energostatic control of feeding (Booth, 1972). Although sweet carbohydrates induce some positive feedback for eating through oral afferent stimulation, this may be countered by the potent inhibitory action via postingestive and postabsorptive mechanisms. Appropriate experiments should demonstrate whether or not this is the case.

One clear finding from these studies is that carbohydrates are efficient appetite suppressants, that is, they contribute markedly to the satiating efficiency of food and exert a potent effect on satiety (Rogers et al. 1988; Blundell et al. 1994). This evidence is precisely complemented by studies showing that an analogue of glucose, 2-deoxy-D-glucose (which blocks the utilization of glucose by cells), actually increases hunger when given to human subjects (Thompson \& Campbell, 1977). On the basis of studies on rats, it was argued some years ago that "if the cumulative inhibitory effects of carbohydrate on feeding are indeed energostatic...then any substance which can readily be used by the animal to provide energy should produce an appropriate food intake compensation over a period of several hours after loading'. Studies have shown that this is exactly the same in humans. A variety of carbohydrates, including glucose, fructose, sucrose, and maltodextrins, have rather similar effects when given in a preload: they suppress later intake by an amount roughly equivalent to their calorie value, although the time course of the suppressive action may vary according to the rate at which the carbohydrate loads are metabolized (Van Amelsvoort \& Weststrate, 1992).

\section{Fat and satiety signals}

Many people believe that eating fat provides a strong feeling of fullness which would be consistent with a potent action on satiety. However, exposure to a diet containing high fat foods leads to immediate overconsumption in a single meal (Lawton et al. 1993), over days (Tremblay et al. 1989) or weeks (Lissner et al. 1987). This paradox can be expressed as the puzzle of fat induced satiety and high fat hyperphagia.

Indeed, fat in the intestine does generate potent satiety signals (Read, 1992). Infusions of intralipid (an emulsified fat) into the ileum (Welch et al. 1985) or jejunum (Welch et al. 1988) reduced the size of a test meal, increased feelings of fullness and slowed gastric emptying. However, intralipid infused intravenously had no inhibitory effect on appetite. Similar effects have been generated in rats (Greenberg et al. 1992). Taken together these studies demonstrate that fat in the intestine generates potent pre-absorptive satiety signals, probably mediated, at least in part, by a cholecystokinin mechanism.

However, when rats are placed on high fat diets or given fat supplements they take in excessive amounts of energy and rapidly gain weight. Moreover, as noted above, human subjects exposed to a range of high fat foods increase meal size and energy intake. What is the explanation for the apparent contradiction between fat induced satiety signals and the easy overconsumption of high fat foods?

Although pure emulsified fat delivered to the intestine produces prompt satiety signals, consumed fat will take some time to reach the intestine in similar form and its action is 
likely to be diluted by other nutrients. Hence consumed fat may have a weaker effect on key receptors and the satiety signals may arise more slowly. Two features of fat favour the rapid consumption of energy. Firstly, fat produces potent oral stimulation which facilitates intake, and secondly, high fat foods normally have a high energy density. This means that a large amount of fat energy can be consumed before the fat induced satiety signals become operative.

Consequently, although fat induces strong pre-absorptive satiety signals these do not appear to be capable of preventing overconsumption when the diet contains high fat foods. The inhibition of fat intake may therefore depend upon postabsorptive signals. However, the presence of circulating lipids per se does not appear to generate satiety in rats or humans (see above). Moreover, the concept of fuel balance does not appear to provide a mechanism which can rapidly or strongly restrict the consumption of fat (when the diet contains high fat foods). However, it has been argued that the oxidation of fuels (carbohydrate and fat) does represent a stimulus for satiety (Friedman et al. 1986; Friedman, 1991). How can these ideas be integrated with the features of the fuel balance hypothesis?

\section{Fuel balance and satiety}

If explanations for the satiating actions of macronutrients are to be found in the mechanisms responsible for fuel balance, then protein and carbohydrate would appear to differ from fat. As noted, the intakes of protein and carbohydrate are restricted by storage capacity and also tightly coupled to their rates of oxidation. This is consistent with the effects of these nutrients on satiety although the mechanisms which inhibit the pattern of food intake are certainly pre-absorptive as well as postabsorptive.

One important issue relates to the phenomenon of high fat hyperphagia. When subjects eat from a range of high fat low carbohydrate foods energy intake increases. Is this an active or passive process? One argument arising from the concept of fuel balance is that satiety occurs when carbohydrate balance has been met (glycogen stores replenished). Therefore, when metabolic pathways maintaining carbohydrate balance do not permit the adjustment of carbohydrate availability for oxidation, consumption continues until a particular intake of carbohydrate allowing carbohydrate balance has been achieved (Tremblay, 1994). This would represent an active process. Alternatively, the high energy intake of high fat foods has been termed 'passive overconsumption' (Blundell et al. 1993) since it is not driven to meet a need but is induced by high palatability and high energy density.

Recent experiments by Stubbs (1993) have thrown light on this issue. When subjects were presented with isocaloric high fat or high carbohydrate diets energy intakes were approximately equal. This means that the phenomenon of high fat hyperphagia is largely caused by the high energy density rather than by the proportion of fat. This failure to overeat on the high fat/low carbohydrate diet also suggests that intake is not stimulated by the need to achieve a particular level of CHO intake. However, if appetite is not stimulated by low CHO (possible due to the potent pre-absorptive satiety effect of the fat) it does appear that appetite is potently suppressed by high CHO foods. Stubbs observed significant undereating on a high carbohydrate diet. Consequently, the fuel balance hypothesis is consistent with high carbohydrate induced satiety.

\section{Implications for obesity}

The experimental evidence described above suggests that lipid balance is the buffer of the overall fuel balance because it ultimately accommodates the deviations in protein and carbohydrate balance. Furthermore, since lipid oxidation is not acutely affected by changes 
in lipid intake, its variations could theoretically play a major role in the predisposition to become obese.

Two experimental strategies have been recently used to investigate lipid oxidation in individuals predisposed to obesity. Firstly, postobese subjects maintaining a stable body weight were compared to lean controls. This approach allows the comparison of individuals predisposed to obesity with lean subjects while minimizing the confounding effect of body fat accumulation on fat oxidation. In studies where this condition was reasonably respected, daily $R Q$ was found to be significantly greater in postobese subjects, indicating a reduced proportion of lipid in the fuel mix oxidized (Lean \& James, 1988; Buemann et al. 1992).

This issue has also been examined in obese and lean individuals subjected to a high fat diet for one week (Thomas et al. 1992). A highly significant correlation was observed between daily fat intake and fat oxidation at the end of the protocol in lean subjects whereas essentially no association was found between these two variables in the obese group. Obese subjects were less able to regulate fuel and energy balance because of a decreased capacity to increase lipid oxidation when receiving a high fat diet.

In summary, people predisposed to obesity are characterized by a reduced capacity to oxidize lipid when their adiposity is normal. In addition, they seem to be low responders in lipid oxidation when exposed to conditions favouring a positive lipid balance. In this context, body fat gain becomes a necessary condition to restore lipid balance because fat gain per se promoted an increase in fat oxidation (Groop et al. 1991; Schultz et al. 1992). As recently described (Tremblay, 1992), this fat gain can be large enough to lead to obesity before a new lipid balance is reached.

Observations show that mechanisms regulating fuel and energy balance cannot rapidly restore homeostasis when the proportion of lipid in the diet is increased. The resulting energy intake necessarily requires a storage of body energy which will persist as long as fat oxidation does not restore fat balance. As discussed above, this adaptation of lipid oxidation seems to be a weak component in the regulating system of individuals predisposed to obesity.

A treatment of obesity based on fuel balance is not only aimed at inducing an energy deficit but should also provoke a concordant fuel imbalance. However, considering the importance and the priority of maintaining protein and carbohydrate balance, this fuel imbalance is equivalent to a lipid deficit. In other words, obesity treatment should result in a lipid deficit without significant perturbations of protein and carbohydrate balance. At least three recommendations are appropriate to reach this goal. Firstly, the proportion of lipid in the diet should be reduced in order to decrease energy intake while maintaining carbohydrate intake and satiety. Secondly, since alcohol has been shown to reduce lipid oxidation (Suter et al. 1992), its consumption should be markedly reduced to favour a negative lipid balance. Finally, obese persons should be encouraged to perform regular aerobic exercise which is known to increase lipid oxidation both during exercise and for many hours after its completion (Bielinski et al. 1985; Tremblay et al. 1985).

If an obese person strictly respects these recommendations, substantial weight and fat losses should be obtained without experiencing discomfort and hunger. The ability of the body to tolerate these energy and lipid deficits is however not unlimited. Indeed, it is important to keep in mind that changes in body fatness influence fat balance. As illustrated in Fig. 5, for a given energy intake any decrease in fat oxidation will be accompanied by an increase in the absolute level of carbohydrate oxidation, even if energy expenditure is diminished. The increase in carbohydrate oxidation should normally be sensed by the system and be associated with an increase in energy intake. This implies that the ability of the body to tolerate a spontaneous lipid and energy deficit should progressively decrease 


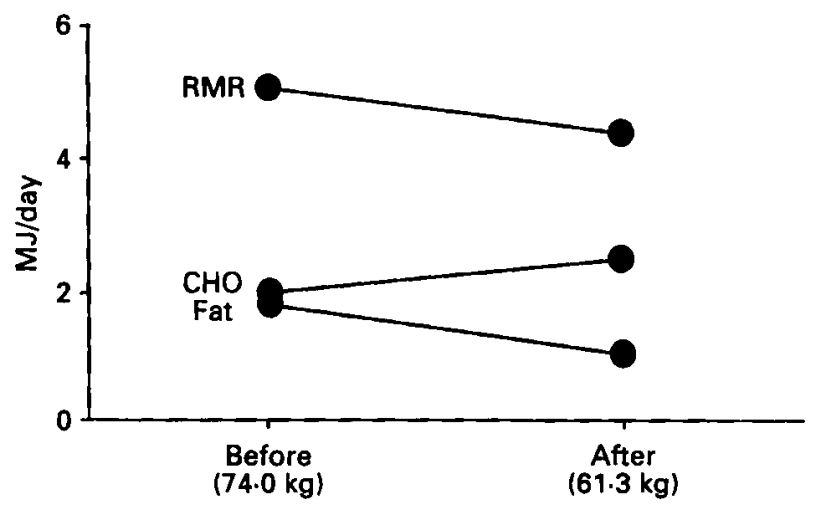

Fig. 5. Mean resting energy expenditure and substrate oxidation in obese women before and after body weight reduction. Adapted from Schutz et al. (1992).

with fat loss until a threshold beyond which any additional fat loss would become a source of discomfort. In a recent study, we used this approach in obese women who were able to lose about $14 \mathrm{~kg}$ body weight before experiencing resistance to fat loss (Tremblay et al. $1991 b$ ).

This description of the fuel balance view disclosed a contrast with other metabolic theories of satiety (e.g. Friedman, 1991) concerning the role of oxidation. The fuel balance hypothesis contains the argument that an increase in CHO oxidation should be followed by an increase in energy intake (i.e. a stimulation of appetite). However, Friedman's view is that $\mathrm{CHO}$ oxidation is a signal for satiety (i.e. inhibition of appetite). Evidence for this latter view is that blockade of CHO oxidation by 2-deoxy-D-glucose stimulates eating in rats and increases hunger in humans. The precise role of carbohydrate oxidation in initiating, terminating or modulating energy intake therefore remains to be resolved.

\section{Fuel balance and appetite control - is there a relationship?}

The expression of appetite involves a pattern of eating behaviour and oscillations in the strength and direction of motivation to eat (hunger and food preferences) which result in an intake of energy with a particular nutrient composition. The fuel balance hypothesis does not provide a full account for the control of appetite. A working hypothesis could be that metabolic consequences of nutrient ingestion exert inhibitory effects on appetite, and that appetite is driven in part by the metabolic consequences of decreased nutrient ingestion. The task is to define those circumstances under which the metabolic state exerts an effect on the feeling of hunger and the behaviour of eating.

There is some concordance between the appetite for particular diets and the disposition of metabolic fuels in the body. Firstly, a high carbohydrate diet is associated with an increase in CHO oxidation and strong satiety. According to Friedman (1991) the increase in oxidation is a mechanism for satiety. On this type of diet energy intake is limited (presumably by the satiety induced). This is biologically appropriate since there is limited storage for CHO in the body. The same arguments can be applied to a high protein diet although the evidence is more sparse. Therefore fuel balance concepts are consistent with a biological limitation of intakes on high $\mathrm{CHO}$ and high protein diets.

Secondly, a high fat diet (range of high fat foods) can overcome potent pre-absorptive fat induced satiety signals and lead to a high energy intake (high fat hyperphagia). Since lipid oxidation is only weakly coupled to lipid intake and lipid storage is not too restricted, only a weak inhibition of appetite arises from the metabolic consequences of a high fat diet. 
Therefore the demonstrated effects of high fat diets are consistent with concepts of fuel balance.

Current evidence suggests that the pattern of eating behaviour is not driven by the metabolic consequences of nutrient ingestion. Indeed there is evidence that a stable pattern of food (and nutrient) intake can persist in the face of drastic adjustments in the metabolic profile (Stubbs, 1993). The metabolic profile (patterns of fuel oxidation etc.) certainly follows from the prior pattern of ingestion but does not necessarily provide strong feedback to adjust eating, at least in the short term.

However, this does not mean that appetite control is completely divorced from fuel balance. In certain circumstances (high carbohydrate and high protein diets) there is apparent congruence between metabolic activity and eating behaviour. But on other occasions there is no relationship. This means that the expression of appetite is controlled by factors other than metabolic variables. At times these other factors can overwhelm any metabolic drive. This is of course obvious. The pattern of food and nutrient intake is influenced by the composition of the diet available, by its palatability and accessibility, and of course by oral afferent receptors, pre-absorptive mechanisms and the activity of specific neuromodulators in the brain.

In addition, there is good evidence that appetite, reflected in energy intakes, is not closely regulated on a day-to-day basis (Tarasuk \& Beaton, 1991). These large daily fluctuations suggest that there is no biological imperative to control appetite precisely. (Of course a strong metabolic drive (arising from need states) would arise if intake fell markedly below expenditure.) Metabolic adaptations can accommodate wide fluctuations in intake. One such adaptation is the enlargement of adipose tissue stores.

Is the preservation of energy balance a primary biological goal for human beings? There is ample evidence that in technologically advanced societies, and in some which are not, many people exist in a state of positive energy balance. This means that the willingness to consume energy (food) is not apparently hindered by inadequate energy expenditure. This situation is favoured by particular dietary regimes and the fuel balance concept provides a cogent explanation for this. Fuel balance notions also indicate where physiological mechanisms and nutrient recommendations coincide to produce effective appetite control. However the enactment of these principles depends upon enforcement or strict psychological compliance. The principles themselves do not automatically ensure biologically appropriate behaviour. For this reason it is likely that those mechanisms of appetite control which are not influenced by fuel oxidation will continue to be at least as important as those which are so influenced.

\section{REFERENCES}

Acheson, K. J., Schutz, Y., Bessard, T., Anantharaman, K., Flatt, J.-P. \& Jéquier, E. (1988). Glycogen storage capacity and de novo lipogenesis during massive carbohydrate overfeeding in man. American Journal of Clinical Nutrition 48, 240-247.

Bielinski, R., Schutz, Y. \& Jéquier, E. (1985). Energy metabolism during the postexercise recovery in man. American Journal of Clinical Nutrition 42, 69-82.

Blundell, J. E. (1991 a). The biology of appetite. Clinics in Applied Nutrition 1, 21-31.

Blundell, J. E. $(1991$ b). Pharmacological approaches to appetite suppression. Trends in Pharmacological Sciences 12, 147-157.

Blundell, J. E., Green, S. \& Burley, V. (1994). Carbohydrates and human appetite. American Journal of Clinical Nutrition 59 (Suppl.), 728S-734S.

Blundell, J. E. \& Hill, A. J. (1986). Biopsychological interactions underlying the study and treatment of obesity. In The Psychosomatic Approach: Contemporary Practice of Whole Person Care, pp. 115-138 [M. J. Christie and P. G. Mellett, editors]. Chichester: Wiley.

Blundell, J. E., Lawton, C. L. \& Hill, A. J. (1993). Mechanisms of appetite control and their abnormality in obese patients. Hormone Research 39, 72-76. 
Blundell, J. E. \& Rogers, P. J. (1991). Hunger, hedonics and the control of satiation and satiety. In Chemical Senses, vol. 4, Appetite and Nutrition, pp. 127-148 [M. Friedman and M. Kare, editors]. New York: Marcel Dekker Inc.

Blundell, J. E. \& Rogers, P. J. (1994). Sweet carbohydrate substitutes (intense sweeteners) and the control of appetite: scientific issues. In Appetite and Body Weight Regulation-Sugar, Fat and Macronutrient Substrates, pp. 113-124 [J. D. Fernstrom and G. D. Miller, editors]. Boca Raton, FL: CRC Press.

Booth, D. A. (1972). Postabsorptively induced suppression of appetite and the energostatic control of feeding. Physiology and Behavior 9, $199-202$.

Bouchard, C. (1985). Inheritance of fat distribution and adipose tissue metabolism. In Metabolic Complications of Human Obesities, pp. 87-96 [J. Vague, P. Björntorp, B. Guy-Grand, M. Rebuffé-Scrive and P. Vague, editors]. Amsterdam: Excerpta Medica.

Buemann, B., Astrup, A., Christensen, N. J. \& Madsen, J. (1992). Effect of moderate cold exposure on 24-h energy expenditure: similar response in postobese and nonobese women. American Journal of Physiology 263, E1040-E1045.

Campfield, L. A., Brandon, P. \& Smith, F. J. (1985). On-line continuous measurement of blood glucose and meal pattern in free-feeding rats: the role of glucose in meal initiation. Brain Research Bulletin 14, 605-616.

De Castro, J. M. (1987). Macronutrient relationships with meal patterns and mood in the spontaneous feeding behavior of humans. Physiology and Behavior 39, 561-569.

Fernstrom, J. D. \& Faller, D. V. (1978). Neutral amino acids in the brain: changes in response to food ingestion. Journal of Neurochemistry 30, 1531-1538.

Fernstrom, J. D. \& Wurtman, R. J. (1972). Brain serotonin content: physiological regulation by plasma neutral amino acids. Science 178, 414-416.

Flatt, J.-P. (1987). Dietary fat, carbohydrate balance, and weight maintenance: effects of exercise. American Journal of Clinical Nutrition 45, 296-306.

Flatt, J.-P., Ravussin, E., Acheson, K. J. \& Jéquier, E. (1985). Effects of dietary fat on postprandial substrate oxidation and on carbohydrate and fat balances. Journal of Clinical Investigation 76, 1019-1024.

Friedman, M. I. (1990). Body fat and the metabolic control of food intake. International Journal of Obesity 14 (Suppl. 3), 53-67.

Friedman, M. I. (1991). Metabolic control of calorie intake. In Chemical Senses, vol. 4, Appetite and Nutrition, pp. 19-38 [M. I. Friedman, M. G. Tordoff and M. K. Kare, editors]. New York: Marcel Dekker Inc.

Friedman, M. I., Tordoff, M. G. \& Ramirez, I. (1986). Integrated metabolic control of food intake. Brain Research Bulletin 17, 855-859.

Greenberg, D., Smith, G. P. \& Gibbs, J. (1992). Cholecystokinin and the satiating effect of fat. Gastroenterology 102, 1801-1802.

Groop, L. C., Bonadonna, R. C., Shank, M., Petrides, A. S. \& DeFronzo, R. A. (1991). Role of free fatty acids and insulin in determining free fatty acid and lipid oxidation in man. Journal of Clinical Investigation 87, 83-89.

Hill, A. J. \& Blundell, J. E. (1988). Role of amino acids in appetite control in man. In Amino Acid Availability and Brain Function in Health and Disease, pp. 239-248 [G. Huether, editor]. Berlin: Springer-Verlag.

Jéquier, E. (1990). Nutrient balance in body weight regulation: its importance in the development of obesity in man. In Progress in Obesity Research 1990, pp. 157-160 [Y. Oomura et al., editors]. London: John Libbey.

Kendall, A., Levitsky, D. A., Strupp, B. J. \& Lissner, L. (1991). Weight loss on a low fat diet: consequence of the imprecision of the control of food intake in humans. American Journal of Clinical Nutrition 53, 1124-1129.

Kennedy, G. C. (1953). The role of depot fat in the hypothalamic control of food intake in the rat. Proceedings of the Royal Society, London, Ser. B 140, 578-592.

Langhans, W. \& Scharrer, E. (1987). Evidence for a vagally mediated satiety signal derived from hepatic fatty acid oxidation. Journal of the Autonomic Nervous System 18, 13-18.

Lawton, C. L., Burley, V. J., Wales, J. K. \& Blundell, J. E. (1993). Dietary fat and appetite control in obese subjects: weak effects on satiation and satiety. International Journal of Obesity 17, 409-416.

Lean, M. E. J. \& James, W. P. T. (1988). Metabolic effects of isoenergetic nutrient exchange over 24 hours in relation to obesity in women. International Journal of Obesity 12, 15-27.

Lissner, L., Levitsky, D. A., Strupp, B. J., Kalkwarf, H. J. \& Roe, D. A. (1987). Dietary fat and the regulation of energy intake in human subjects. American Journal of Clinical Nutrition 46, 886-892.

Mayer, J. (1953). Glucostatic mechanism of regulation of food intake. New England Journal of Medicine 249 , 13-16.

Mayer, J. \& Thomas, D. W. (1967). Regulation of food intake and obesity. Science 156, 328-337.

Mei, N. (1985). Intestinal chemosensitivity. Physiological Reviews 65, 211-237.

Mellinkoff, S. M., Boyle, D., Frankland, M. \& Greipel, M. (1955). The effect of amino acid administration upon the blood sugar concentration. Stanford Medical Bulletin 13, 117-124.

Oomura, Y. (1988). Chemical and neuronal control of feeding motivation. Physiology and Behavior 44, 555-560.

Powley, J. (1977). The ventromedial hypothalamic syndrome, satiety and a cephalic phase hypothesis. Physiological Reviews 84, 89-126.

Prentice, A. M., Black, A. E., Murgatroyd, P. R., Goldberg, G. R. \& Coward, W. A. (1989). Metabolism or appetite: questions of energy balance with particular reference to obesity. Journal of Human Nutrition and Dietetics 2, 95-103. 
Read, N. W. (1992). Role of gastrointestinal factors in hunger and satiety in man. Proceedings of the Nutrition Society 51, 7-11.

Richter, C. P. (1943). Total self-regulatory functions in animals and human beings. Harvey Lectures 38, 63-103.

Rogers, P. J., Carlyle, J.-A., Hill, A. J. \& Blundell, J. E. (1988). Uncoupling sweet taste and calories: comparison of the effects of glucose and three intense sweeteners on hunger and food intake. Physiology and Behavior 43, $547-552$.

Schutz, Y., Tremblay, A., Weinsier, R. L. \& Nelson, K. M. (1992). Role of fat oxidation in the long-term stabilization of body weight in obese women. American Journal of Clinical Nutrition 55, 670-674.

Shah, M., McGovern, P., French, S. \& Baxter, J. (1994). Comparison of a low-fat, ad libitum complexcarbohydrate diet with a low-energy diet in moderately obese women. American Journal of Clinical Nutrition 59, $980-984$.

Smith, G. P., Greenberg, D., Corp, E. \& Gibbs, J. (1990). Afferent information in the control of eating. In Obesity: Towards a Molecular Approach, pp. 63-79 [G. A. Bray, editor]. New York: Alan R. Liss.

Stubbs, R. J. (1993). Macronutrients, Appetite and Energy Balance in Humans. PhD thesis, University of Cambridge.

Stubbs, R. J., Murgatroyd, P. R., Goldberg, G. R. \& Prentice, A. M. (1993). Carbohydrate balance and the regulation of day-to-day food intake in humans. American Journal of Clinical Nutrition 57, 897-903.

Suter, P. M., Schutz, Y. \& Jéquier, E. (1992). The effect of ethanol on fat storage in healthy subjects. New England Journal of Medicine 326, 983-987.

Tarasuk, V. \& Beaton, G. H. (1991). The nature and individuality of within-subject variation in energy intake. American Journal of Clinical Nutrition 54, 464-470.

Thomas, C. D., Peters, J. C., Reed, G. W., Abumrad, N. N., Sun, M. \& Hill, J. O. (1992). Nutrient balance and energy expenditure during ad libitum feeding of high-fat and high-carbohydrate diets in humans. American Journal of Clinical Nutrition 55, 934-942.

Thompson, D. A. \& Campbell, R. G. (1977). Hunger in humans induced by 2-deoxy-D-glucose: glucoprivic control of taste preference and food intake. Science 198, 1065-1068.

Tremblay, A. (1992). Human obesity: a defect in lipid oxidation or in thermogenesis? International Journal of Obesity 16, 953-957.

Tremblay, A. (1994). Nutritional determinants of the insulin resistance syndrome. International Journal of Obesity, in press.

Tremblay, A., Coveney, S., Després, J.-P., Nadeau, A. \& Prud'homme, D. (1992). Increased resting metabolic rate and lipid oxidation in exercise-trained individuals: evidence for a role of $\beta$-adrenergic stimulation. Canadian Journal of Physiology and Pharmacology 70, 1342-1347.

Tremblay, A., Després, J.-P., Majeux, J., Pouliot, M.-C., Nadeau, A., Moorjani, S., Lupien, P. J. \& Bouchard, C. $(1991 b)$. Normalization of the metabolic profile in obese women by exercise and a low fat diet. Medicine and Science in Sports and Exercise 23, 1326-1331.

Tremblay, A., Fontaine, E. \& Nadeau, A. (1985). Contribution of postexercise increment in glucose storage to variations in glucose-induced thermogenesis in endurance athletes. Canadian Journal of Physiology and Pharmacology 63, 1165-1169.

Tremblay, A., Lavallée, N., Alméras, N., Allard, L., Després, J.-P. \& Bouchard, C. (1991a). Nutritional determinants of the increase in energy intake associated with a high-fat diet. American Journal of Clinical Nutrition 53, $1134-1137$.

Tremblay, A., Plourde, G., Després, J.-P. \& Bouchard, C. (1989). Impact of dietary fat content and fat oxidation on energy intake in humans. American Journal of Clinical Nutrition 49, 799-805.

Van Amelsvoort, J. M. M. \& Westrate, J. A. (1992). Amylose-amylopectin ratio in a meal affects postprandial variables in male volunteers. American Journal of Clinical Nutrition 55, 712-718.

Van Stratum, P., Lussenburg, R. N., Van Wezel, L. A., Vergroesen, A. J. \& Cremer, H. D. (1978). The effect of dietary carbohydrate: fat ratio on energy intake by adult women. American Journal of Clinical Nutrition 31, 206-212.

Welch, I., Saunders, K.\& Read, N. W. (1985). Effect of ileal and intravenous infusions of fat emulsions on feeding and satiety in human volunteers. Gastroenterology 89, 1293-1297.

Welch, I. M., Sepple, C. P-\& Read, N. W. (1988). Comparisons of the effects on satiety and eating behaviour of infusion of lipid into the different regions of the small intestine. Gut 29, 306-311.

Young, V. R. \& Marchini, J. S. (1990). Mechanisms and nutritional significance of metabolic responses to altered intakes of protein and amino acids, with reference to nutritional adaptation in humans. American Journal of Clinical Nutrition 51, 270-289.

Zimmet, P. Z. (1992). Kelly West Lecture 1991. Challenges in diabetes epidemiology-from West to the rest. Diabetes Care 15, 232-252. 